\title{
Effects of alcoholic solutions of three salts of metals on some hepatorenal biochemical parameters in albino Wistar rats
}

\author{
Y. Samuel GAZUWA*, N. David PIPKONG and K. Joy POFI
}

Department of Biochemistry, Faculty of Medical Sciences, University of Jos, PMB 2084 Jos, Nigeria.

*Correspondence author; E-mail: sygazuwa@gmail.com; gazuwas@unijos.edu.ng

\begin{abstract}
Toxicants are present in alcoholic drinks both of which are toxic to the liver and kidney. But do combination of two heavy and one trace metal salts affect the toxicity of alcohol in vivo? This work sought to compare effects of alcohol alone (control), with alcoholic solutions of salts of $\mathrm{Cd}, \mathrm{Pb}, \mathrm{Zn}$ and $\mathrm{Mn}$ on liver and kidney parameters. Further, to compare toxic effects of $\mathrm{Cd}$ and $\mathrm{Pb}$ in presence of $\mathrm{Zn}$ and also in the presence of Mn. To unravel this, 20 male albino Wistar rats were divided into 5 groups of 4 rats each and orally administered appropriate doses of alcoholic solution containing $\mathrm{Pb}\left(\mathrm{CH}_{3} \mathrm{CH}_{2} \mathrm{OO}^{-}\right)_{2}+\mathrm{CdCl}_{2}+\mathrm{ZnSO}_{4}(\mathbf{A})$, in one case and $\mathrm{Pb}\left(\mathrm{CH}_{3} \mathrm{CH}_{2} \mathrm{OO}^{-}\right)_{2}+\mathrm{CdCl}_{2}+\mathrm{MnCl}_{2}(\mathbf{B})$ in the other based on $10 \mathrm{ml} / \mathrm{kg}$ volume selection calculations. Rats were fed once daily and spectrophotometry was applied for the analysis. The control contained 5\% (v/v) alcohol concentration. Treatment with $\mathbf{A}$, for 7 and 14 consecutive days significantly $(\mathrm{p}<0.05)$ elevated serum activities (IU) of aspartate oxaloacetate transaminase (AST), 241.51 \pm 0.47 , alanine transaminase (ALT), $69.43 \pm .35$ compared to control group values except alkaline phosphatase (ALP), 154.86 \pm 0.55 (p>0.05). Mean serum levels of total proteins (TP), in $\mathrm{gdm}^{-3}$, was $73.81 \pm 0.65(\mathrm{p}<0.05)$; levels of urea (UR) and creatinine (CR), $\mathrm{mMoldm}^{-3}$, were $37.38 \pm 0.32$ and $39.75 \pm 0.45$ respectively $(\mathrm{p}<0.05)$ relative control group values. B administered for 7 and 14 days significantly increased $(\mathrm{p}<0.05)$ activities of AST, ALT, ALP as well as ALB, UR $(251.25 \pm 2.11,87.43 \pm 3.12,245.19 \pm 2.31,37.34 \pm 1.49,7.47 \pm 0.64)$ respectively; levels of TP and CR were not significantly higher $(\mathrm{P}>0.05)$ relative control group values. Whereas treatment with $\mathbf{A}$ elevated the hepatic parameters, treatment with $\mathbf{B}$ raised the concentration of the nephrotic parameters. Since cadmium and lead salts were common to both $\mathbf{A}$ and $\mathbf{B}, \mathrm{ZnSO}_{4}$ appeared to mitigate the adverse effects of both salts on the liver better than $\mathrm{MnCl}_{2}$ which, in turn, modulated effects on the kidney better. It would mean therefore that $\mathrm{Cd}$ and $\mathrm{Pb}$ aggravate the hepato-nephrotic toxicity of alcohol. Presence of $\mathrm{Zn}$ and $\mathrm{Mn}$ reduced the adverse effects of the salts on hepatic and nephrotic biochemical parameters in male Wistar rats respectively.
\end{abstract}

(C) 2018 International Formulae Group. All rights reserved.

Keywords: Alcohol, Cadmium, Lead, Zinc, Manganese, Liver, Kidney.

\section{INTRODUCTION}

Alcoholism is a serious problem in almost all countries of the world (Marks et al., 2003). Excessive consumption of alcoholic beverages is common in both men and women of different age groups within the study area. Ethyl alcohol and some metabolites such as ethanal in 'brew' are the main intoxicating substance in all alcoholic drinks. Gazuwa et al (2006) reported significant levels of iron in burukutu and pito brewed in both metallic and clay containers. These native beers were also reported to be contaminated with zinc and manganese (Gazuwa et al., 2008). Alcoholic 
solutions of $\mathrm{Fe}\left(\mathrm{NO}_{3}\right)_{3}$, and $\mathrm{CdCl}_{2}$, aggravate the toxicity of alcohol (Gazuwa et al., 2012). Sherlock et al (2009) have reported that consumption of 11/day of wine containing $150 \mu \mathrm{g} / 1$ of lead could also make a major contribution to blood lead levels.

Also, consumption of beer containing $50 \mu \mathrm{g} / \mathrm{l}$ of lead could make a substantial contribution to blood lead concentrations in man. Lead contamination of wine when poured from a bottle lead-capped, can sometimes greatly increase lead concentrations in the wine (Sherlock et al., 2009). Combination of cadmium and lead administered to rats was reported to cause hepatic necrosis thereby elevating the activities of AST and ALP; iron combined with zinc and iron combined with lead elevated the activity of ALT (Gazuwa et al., 2014). Generally, binary mixtures of salts of these metals in alcohol appear to enhance its toxicity on hepatic biochemical parameters. On nephrotic parameters $\mathrm{Cd}$ and $\mathrm{Pb}$ salts in alcohol caused a very significant increase in the level of serum urea (Gazuwa et al., 2014; Gazuwa et al., 2012). Cadmium and alcohol are toxic to cells and their co-administration has been reported to cause urinary protein excretion (Gazuwa et al., 2014); also, coadministration with iron and cadmium salts caused increase the level of serum creatinine (Gazuwa et al., 2014). Excessive and continuous intake of alcohol leads to extensive tissue damage in organs such as the liver, heart, kidney and the respiratory system (Brust, 2010). This work sought to compare effects of alcohol alone (control), with alcoholic solutions of salts of $\mathrm{Cd}, \mathrm{Pb}, \mathrm{Zn}$ and $\mathrm{Mn}$ on liver and kidney parameters. Further, to compare toxic effects of $\mathrm{Cd}$ and $\mathrm{Pb}$ in presence of $\mathrm{Zn}$ and also in the presence of Mn.

\section{MATERIALS AND METHODS \\ Chemicals and Reagents}

Chemicals: $\quad \mathrm{Pb}\left(\mathrm{C}_{2} \mathrm{H}_{3} \mathrm{OH}\right)_{2}, \quad \mathrm{CdCl}_{2}$, $\mathrm{ZnSO}_{4}, \mathrm{MnCl}_{2}, 5 \%$ ethyl alcohol and all other chemical used were of analytical grade.

AlkalinePhosphatase (ALP): Reagent composition: $1 \times 7 \mathrm{ml}$ chromogenic substrate,
$2 \times 250 \mathrm{ml}$ colour developer, the content of the vial was dissolved in $250 \mathrm{ml}$ water, $1 \times$ $5 \mathrm{ml}$ standard solution equivalent to $3 \mu / \mathrm{L}$. The composition of the reagent solution was $2-$ amino-2-methyl-1-propanol (pH 11.7), phenolphthalein monophosphate $63 \mathrm{mM}$, $\mathrm{NaHPO}_{4} 80 \mathrm{mM}$, stabilisers and preservatives.

Albumin: The reagent contained albumin reagent $5 \times 50 \mathrm{ml}$, succinate buffer (pH 4.20) $75 \mathrm{mMo} 1 / \mathrm{L}$, Bromocresol green $0.14 \mathrm{~g} / \mathrm{L}$, albumin standard $1 \times 3 \mathrm{ml}$ and albumin standard $(3 \mathrm{gm} / \mathrm{dL})$.

AspartateAminotransferase (AST):

The components of reagent 1 were; buffer (Tris, PH 7.8) $280 \mathrm{mMol} / \mathrm{L}$, L-aspartate 800 $\mathrm{mMol} / \mathrm{L}$, malate dehydrogenase $>2.1 \mathrm{kU} / \mathrm{L}$, Lactate dehydrogenase $>3.0 \mathrm{kU} / \mathrm{L}$, preservatives, detergent and stabilisers. Reagent 2 contained NADH $>1.7 \mathrm{mMol} / \mathrm{L}, \alpha-$ ketoglutarate, di-Na $94 \mathrm{mMol} / \mathrm{L}$ and preservative.

Alanine Aminotransferase (ALT): Reagent 1 contained buffer (Tris, PH 7.3) 230 $\mathrm{mMol} / \mathrm{L}, \mathrm{L}$ - alanine $1100 \mathrm{mMol} / \mathrm{L}$, lactate dehydrogenase $>2.1 \mathrm{kU} / \mathrm{L}$, preservatives, detergent and stabilizers. Reagent 2 was composed of NADH $(1.7 \mathrm{mMol} / \mathrm{L}) \quad \alpha-$ ketoglutarate, di-Na $95 \mathrm{mMol} / \mathrm{L}$ and preservative.

Total Protein (TP): Reagent composition: $\mathrm{NaOH} 600 \mathrm{mM}, \mathrm{CuSO} 4(12$ $\mathrm{mMol}$ ), sodium potassium tartarate (32 $\mathrm{mMol})$, potassium iodide $(30 \mathrm{mMol})$.

Total protein standard: Bovine albumin $(5.0 \mathrm{~g} / \mathrm{dl})$ with preservative.

Serum Creatinine (CR) Reagent composition: Reagent1 was composed of alkaline buffer $(\mathrm{NaOH})$; Reagent2: picric acid (40 mMol), surfactant.

Urea (UR) Reagent composition: Reagent 1: sodium salicylate $(60.02 \mathrm{mMol} / \mathrm{L})$, Sodium nitroprusside $5 \mathrm{mMol} / \mathrm{L}$. Reagent 2 contained urease $(>4 \mathrm{U} / \mathrm{ml})$. Reagent 3 was composed of $\mathrm{HCl}$ solution $(4 \% \mathrm{w} / \mathrm{v}: 20 \mathrm{ml})$. Reagent 4 had urea standard $(40 \mathrm{mg} / \mathrm{dL})$.

\section{Study subjects}

Twenty male albino Wistar rats purchased from the animal house of the Department of Pharmacology, University of 
Jos, Nigeria. Administration of samples to animals was performed in the laboratory of the same animal house. Other bench work was carried out in the laboratory of the Department of Biochemistry, University of Jos.

\section{Experimental Design}

A total of 20 rats were kept in a cage for 4 weeks to acclimatise. They were thereafter divided into 5 groups of 4 rats each in separate cages. Alcoholic solution was orally administered once/day. Duration of the administration lasted for 7 , and 14 days consecutively. Animals were fed standard pelletised feeds obtained from Grand cereals and oil mills limited, Jos. Concentration of alcoholic solution was 5\% ethyl alcohol (v/v). $0.1 \mathrm{~g}$ of each of the metal salts was dissolved in the $5 \%(\mathrm{v} / \mathrm{v})$ alcoholic solution. Based on $10 \mathrm{ml} / \mathrm{kg}$ body weight (b.w) volume selection, required dose volumes for each group were calculated thus: weight of animal (g)/1000gx 10ml (Erhirhie et al., 2014).

Group 1: mean weight of rats for this group was 177.2 g. Each rat was administered 3.54 $\mathrm{ml}$ of 5\% alcoholic solution containing $\mathrm{CdCl}_{2}$, $\mathrm{Pb}\left(\mathrm{C}_{2} \mathrm{H}_{3} \mathrm{O}_{2}\right)_{2}$, and $\mathrm{ZnSO}_{4}$ for 7 consecutive days.

Group 2: mean weight of animals for this group $165.5 \mathrm{~g}$. Each rat was administered 3.31 $\mathrm{ml}$ of $5 \%$ alcoholic solution containing $\mathrm{CdCl}_{2}$, $\mathrm{Pb}\left(\mathrm{C}_{2} \mathrm{H}_{3} \mathrm{O}_{2}\right)_{2}$, and $\mathrm{ZnSO}_{4}$ for 14 consecutive days.

Group 3: mean weight of rats for this group was 169.3 g. Each rat was administered 3.38 $\mathrm{ml}$ of $5 \%$ alcoholic solution containing $\mathrm{CdCl}_{2}$, $\mathrm{Pb}\left(\mathrm{C}_{2} \mathrm{H}_{3} \mathrm{O}_{2}\right)_{2}$, and $\mathrm{MnCl}_{2}$ for 7 days.

Group 4: mean weight of animals was $174.5 \mathrm{~g}$. Each rat was administered $3.48 \mathrm{ml}$ of $5 \%$ alcoholic solution containing $\mathrm{CdCl}_{2}$, $\mathrm{Pb}\left(\mathrm{C}_{2} \mathrm{H}_{3} \mathrm{O}_{2}\right)_{2}$, and $\mathrm{MnCl}_{2}$ for 14 days.

Group 5 (Control): mean weight of animals was $172.21 \mathrm{~g}$. Each rat was administered 3.43 $\mathrm{ml}$ of $5 \%(\mathrm{v} / \mathrm{v})$ alcohol only.

\section{Blood sample collection}

Rats were anaesthesised using
chloroform in an air-tight tank. The

unconscious rats were then dissected longitudinally using forceps/blades along the thoracic region. Blood samples were obtained by direct cardiac puncture using needle and syringe. Blood samples were allowed to clot (20 minutes) before centrifugation at 3000rpm for 10 minutes using bench top centrifuge machine (model RL.1014).

The sera were separated from the clotted portion of blood using new plastic droppers in each case. Cobas C311 autoanalyser equipment was used to analyse the samples. Parameters assayed were: amino transferases (AST and ALT), alkaline phosphatase (ALP), albumin (ALB), total protein (TP), urea (UR) and creatinine (CR).

\section{Determination of serum Total Protein}

The method of Gornail et al (1949), based on biuret method was applied. The protocol was performed at $546 \mathrm{~nm}$. Copper (II) ions form a complex with peptides bonds producing a violet colour coordination complex at alkaline $\mathrm{pH}$ suitable for photometric determination. Absorbance of the complex is directly proportional to the concentration of protein in the sample.

\section{Determination of serum Albumin.}

Same as for total proteins above.

\section{Assay of the activities of ALT, AST and ALP}

Reitman and Frankel method (1957) was applied. For ALT and AST assay, NADH oxidation to $\mathrm{NAD}^{+}$was monitored. In the case of ALP, the rate of conversion of $\mathrm{p}$ nitrophenyl phosphate in the presence of 2amino-2- methyl-1-propanol (AMP) at $\mathrm{pH}$ 10.4 was monitored.

\section{Determination of serum creatinine}

This was performed using Bonses and Tausskay (1945) method. Creatinine reacts with picric acid in alkaline conditions to form a colour complex that absorbs maximally at $510 \mathrm{~nm}$. The rate of colour formation is proportional to the creatinine in the sample. 


\section{Determination of serum urea}

Fearon reaction method (1939) was applied. Urease catalyses the conversion of urea into ammonia and $\mathrm{CO}_{2}$. Ammonia released reacts with salicylate in the presence of nitroprusside and hydrogen chloride giving a blue colour complex. Absorbance of the coloured solution is directly proportional to the concentration of urea measured at $540 \mathrm{~nm}$.

\section{Statistical analysis}

Instat3 statistical software was applied. Only One way ANOVA was chosen to analyse the data and $\mathrm{P}=0.05$ was considered significant.

\section{RESULTS}

Table 1 gives the result of the experiment following 7 days administration of lead cadmium and zinc in 5.0\% ethyl alcohol solution. For AST and ALT, the activities in the test groups are higher $(\mathrm{p}<0.05)$ than the control. Effects on total protein concentration and albumin also show increased activities $(\mathrm{p}<0.05)$ compared to control values. Considering the effect of the treatment on the biochemical markers of the kidney, urea and creatinine levels in the test groups were also higher $(\mathrm{p}<0.05)$ than the control. In the case of alkaline phosphatase activity, test group's activity was lower than the control group values $(\mathrm{P}<0.05)$.

In Table 2, the result obtained shows significant rise in the test param eters following 14 days of the treatment. AST, ALT and ALP activities in the test groups were higher $(\mathrm{p}<0.05)$ compared to the control. Considering the effect of the treatment on total protein and albumin, all the test values are higher $(\mathrm{p}<0.05)$ than the control. For urea and creatinine, effects of the treatment lead to increased values in the test group $(\mathrm{p}<0.05)$ relative to the control value.

From Table 3, treatment for 7 days significantly elevated activities of the transaminases $(\mathrm{P}<0.05)$ but ALP was not significantly different from control group values ( $p>0.05)$. Concentration of UR and TP were elevated significantly $(\mathrm{p}<0.05)$ relative control group values. Administration of solution for 14 days caused a far more increase than for 7 days.

In Table 4, hepatic parameters in the test group were significantly $(\mathrm{p}<0.05)$ higher than the control except TP $(\mathrm{P}>0.05)$. The activity of ALT was significantly $(\mathrm{p}<0.05)$ compared to the control group values indicating likelihood of leakage of the enzyme into circulation although the enzymes exist in isoforms. AST activity in test groups was significantly $(\mathrm{p}<0.05)$ higher than the control group values. The activity of ALP in the test group was also significantly $(\mathrm{P}<0.05)$ higher than the control group. Concentration of ALB in the test group was significantly $(\mathrm{p}<0.05)$ higher relative to the control. As for nephrotic parameters, the level of UR in the test group was significantly $(\mathrm{P}<0.05)$ higher relative to the control group values. Relative control group values, $\mathrm{CR}$ was however not significantly $(\mathrm{p}>0.05)$ higher than control group values.

Table 1: Effects of alcoholic solution containing cadmium, lead and zinc salts on some hepatonephrotic biochemical parameters in Wistar rats following 7 days of treatment.

\begin{tabular}{lccccccc}
\hline Groups & $\begin{array}{c}\text { AST } \\
(\mathbf{I U})\end{array}$ & $\begin{array}{c}\text { ALT } \\
(\mathbf{I U})\end{array}$ & $\begin{array}{c}\text { ALP } \\
(\mathbf{I U})\end{array}$ & $\begin{array}{c}\text { ALB } \\
\left(\mathbf{g} / \mathbf{d m}^{\mathbf{3}}\right)\end{array}$ & $\begin{array}{c}\text { TP } \\
\left(\mathbf{g} / \mathbf{d m}^{\mathbf{3}}\right)\end{array}$ & $\begin{array}{c}\text { UR } \\
\left(\mathbf{m M o l} / \mathbf{d m}^{\mathbf{3}}\right)\end{array}$ & $\begin{array}{c}\text { CR } \\
\left(\mathbf{m M o l} / \mathbf{d m}^{\mathbf{3}}\right)\end{array}$ \\
\hline \multicolumn{7}{c}{} \\
Control & $201.67 \pm 1.34$ & $62.79 \pm 0.30$ & $215.72 \pm 1.56$ & $31.94 \pm 0.43$ & $59.61 \pm 0.87$ & $27.14 \pm 0.55$ & $23.14 \pm 1.81$ \\
Test & $241.51 \pm 0.47^{*}$ & $69.43 \pm 0.35^{*}$ & $154.86 \pm 0.55^{*}$ & $35.96 \pm 0.57$ & $73.81 \pm 0.65^{*}$ & $37.38 \pm 0.32^{*}$ & $39.75 \pm 0.45^{*}$ \\
P-Value & $0.031^{*}$ & $0.041^{*}$ & $0.036^{*}$ & $0.042^{*}$ & $0.045^{*}$ & $0.037^{*}$ & $0.046^{*}$ \\
\hline
\end{tabular}

Values are means of three determinations $( \pm \mathrm{SEM}) ; \mathrm{n}=4)$; IU: International units

*= significantly different compared to the control values. 
Table 2: Effects of alcoholic solution containing cadmium, lead and zinc salts on some hepatonephrotic biochemical parameters in Wistar rats following 14 days of treatment.

\begin{tabular}{lcccccccc}
\hline Groups & $\begin{array}{c}\text { AST } \\
(\mathbf{I U})\end{array}$ & $\begin{array}{c}\text { ALT } \\
(\mathbf{I U})\end{array}$ & $\begin{array}{c}\text { ALP } \\
(\mathbf{I U})\end{array}$ & $\begin{array}{c}\text { ALB } \\
(\mathbf{g} / \mathbf{l})\end{array}$ & $\begin{array}{c}\text { TP } \\
(\mathbf{g} / \mathbf{l})\end{array}$ & $\begin{array}{c}\text { UR } \\
\left(\mathbf{m M o l} / \mathbf{d m}^{3}\right)\end{array}$ & $\begin{array}{c}\mathbf{C R} \\
\left(\mathbf{m M o l} / \mathbf{d m}^{3}\right)\end{array}$ \\
\hline & & & & & & & & \\
Control & $217.74 \pm 2.02$ & $62.12 \pm 0.73$ & $147.18 \pm 0.54$ & $36.29 \pm 1.32$ & $66.49 \pm 0.49$ & $36.15 \pm 1.14$ & $23.23 \pm 0.42$ \\
Test & $254.04 \pm 0.79^{*}$ & $82.17 \pm 0.46^{*}$ & $188.61 \pm 0.49^{*}$ & $39.56 \pm 0.46^{*}$ & $71.81 \pm 0.38$ & $47.54 \pm 0.65^{*}$ & $41.30 \pm 0.46$ \\
P-Value & $0.035^{*}$ & $0.042^{*}$ & $0.041^{*}$ & $0.037^{*}$ & $0.038^{*}$ & $0.045^{*}$ & $0.046^{*}$ \\
\hline
\end{tabular}

Values are means of three determinations; \pm SEM, $(n=4)$.

IU: International units

*statistically significant compared to the control values

Table 3: Effects of alcoholic solution containing cadmium, lead and manganese salts on some hepato-nephrotic biochemical parameters in Wistar rats following 7 days of treatment.

\begin{tabular}{lcccccccc}
\hline Groups & $\begin{array}{l}\text { AST } \\
(\mathbf{I U})\end{array}$ & $\begin{array}{c}\text { ALT } \\
(\mathbf{I U})\end{array}$ & $\begin{array}{c}\text { ALP } \\
(\mathbf{I U})\end{array}$ & $\begin{array}{c}\text { ALB } \\
(\mathbf{g} / \mathbf{l})\end{array}$ & $\begin{array}{c}\text { TP } \\
(\mathbf{g} / \mathbf{l})\end{array}$ & $\begin{array}{c}\mathbf{U R} \\
\left(\mathbf{m M o l} / \mathbf{d m}^{3}\right)\end{array}$ & $\begin{array}{c}\mathbf{C R} \\
\left(\mathbf{m M o l} / \mathbf{d m}^{3}\right)\end{array}$ \\
\hline & & & & & & & \\
Control & $80.11 \pm 1.11$ & $32.12 \pm 0.33$ & $87.81 \pm 1.21$ & $9.08 \pm 2.01$ & $2.45 \pm 1.46$ & $2.15 \pm 0.50$ & $0.12 \pm 0.72$ \\
Test & $129.12 \pm 1.12$ & $41.72 \pm 0.23$ & $89.11 \pm 0.31$ & $14.67 \pm 0.33$ & $3.84 \pm 0.45$ & $3.23 \pm 0.72$ & $0.34 \pm 1.14$ \\
P-Value & $0.015^{*}$ & $0.046^{*}$ & 0.062 & $0.042^{*}$ & $0.048^{*}$ & $0.036^{*}$ & $0.034^{*}$ \\
\hline
\end{tabular}

Values are means of three determinations; \pm SEM, $(n=4)$.

IU: International units

* statistically significant compared to the control values

Table 4: Effects of alcoholic solution containing cadmium, lead and manganese salts on some hepato-nephrotic biochemical parameters in Wistar rats following 14 days of treatment.

\begin{tabular}{lcccccccr}
\hline Groups & $\begin{array}{c}\text { AST } \\
(\mathbf{I U})\end{array}$ & $\begin{array}{c}\text { ALT } \\
(\mathbf{I U})\end{array}$ & $\begin{array}{c}\text { ALP } \\
(\mathbf{I U})\end{array}$ & $\begin{array}{c}\text { ALB } \\
(\mathbf{g} / \mathbf{l})\end{array}$ & $\begin{array}{l}\text { TP } \\
(\mathbf{g} / \mathbf{l})\end{array}$ & $\begin{array}{c}\text { UR } \\
\left(\mathbf{m M o l} / \mathbf{d m}^{\mathbf{3}}\right)\end{array}$ & $\begin{array}{c}\text { CR } \\
\left(\mathbf{m M o l} / \mathbf{d m}^{\mathbf{3}}\right)\end{array}$ & \\
& & & & & & & & \\
\hline
\end{tabular}




\section{DISCUSSION}

The this work sought to monitor the effect of alcoholic solution of salts of lead, cadmium, manganese and zinc on some biochemical parameters of the kidney and liver of albino Wistar rats. Gazuwa et al. (2008) had reported the leaching of walls of brewing vessels, clay or metallic, and water used as sources of metallic toxicants. Ethanol is both hepato- and nephrotoxic through/by oxidative stress and lipid peroxidation leading to hepatic and renal dysfunction (Thomas et al., 2014). Excess alcohol is toxic and affects every organ of the body especially the liver and kidney. Among chronic drinkers, 20\% develop hepatitis or liver cirrhosis. This occurs across a spectrum from fatty liver, to acute alcoholic hepatitis, to cirrhosis or liver cancer (Frank et al., 2004). Even though alcohol is toxic, its toxicity is increased in the presence of heavy metal salts (Gazuwa et al., 2006). Gazuwa et al. (2014) reported that, in alcoholic environment, cadmium and lead salts elevated serum activities of AST, and ALP; also, the levels of UR and CR. Ethanol, due to its amphiphilic property is able to diffuse into all tissues and affect their vital functions (Lieber, 2005). Alcoholic drinks are often contaminated with traces of heavy metals such as cadmium and lead (Gazuwa et al., 2006; Pohl, 2007) which are ingested along with the alcoholic beverages. Alcoholic beverage containers used include metals cans, glass bottles, and paper board cartons which are potential sources of metallic ions in the beverages. For example, zinc is introduced into alcoholic beer by welded cans (Mayer et al., 2003).

In the kidney, ethanol causes renal dysfunction by increasing lipid oxidation, defects in the renal tubules, increased urine volume which alters the body fluid balance (Altamirano, 2012), abnormal serum electrolyte balance and can also alter the form and structure of the kidney (Epstein, 1997).

Results obtained revealed significant increase in the activities of AST, ALT and ALP, as well as concentration of ALB and UR. The enzymes are hepatic biochemical markers which are released into blood circulation as a result of injury to the liver by one or more factors. One factor that can lead to elevated level of these enzymes is excessive and continuous alcohol intake (Asma et al., 2014).

Urea is a biomarker of kidney function whose elevation is a pointer to a compromised and inefficient renal function. Effects on renal parameters from this study showed elevations in creatinine and urea concentrations when compared to the control group. Creatinine is a chemical waste of creatine metabolism from the muscles while urea is the by-product of protein and amino acid metabolism. The major functions of kidney are to regulate the volume of the fluids and electrolytes in the body, supply of nutrients to the cells, excretion of cellular wastes such as urea and creatinine and homeostasis (Vize et al., 2003). High serum urea to creatinine ratio usually indicates impaired kidney function (Maria et al., 2009). In this study, high urea/creatinine ratio was obtained as can be seen from Tables 2, 3, and 4. This implies that treatment with alcoholic solutions of salts of metals for 7 and 14 days may have caused some injuries to the kidneys of the rats used. It may mean that zinc does not confer any protection against combined toxicities of alcohol, cadmium and lead salts to the kidney since high urea/creatinine ratio was obtained following 14 days of treatment. However, from table 1 , the ratio was low following 7 days of treatment in the presence of zinc sulphate. High level of serum urea has been reported as a risk factor in high blood pressure (Kono et al., 2001). Ethanol induces oxidative injury to the kidney (Altamirano et al., 2012). The kidneys could be damaged by ethanol causing the reduction of the renal function by increased lipid peroxidation and 4-hydroxynonenal leading to reduced renal filtration (Altamirano et al., 2012).

Cadmium is detrimental and injurious to nephrons and hepatocytes (Adepoju et al., 2005) and damage several other cells. It accumulates in the liver and kidneys (Lind et al., 1998) causing damage due to its long 
biological half-life (Maduabuchi et al., 2006). Yang et al. (2000) reported that cadmium is better absorbed in the presence of ethyl alcohol. Many of the toxic effects of cadmium on the kidney, liver and the CNS stem from the displacement of zinc from enzyme/receptor binding sites (Aydemir et al., 2006). Albeit $\mathrm{ZnSO}_{4}$ has a protective effect on ethanol-induced liver injury (Sema et al., 2006), ethanol co-administered with zinc has been reported to lower zinc status. This is because ethanol consumption decreases intestinal absorption of zinc and increases urinary zinc excretion (Kang and Zhou, 2005). This leads to zinc deficiency which in turn can lead to intensify cadmium accumulation and toxicity.

Lead in the kidney causes kidney corpuscular necrosis and amiloidosis; in the liver and kidney, the necrotic lesions can be a cause of oxidative stress induced by lead (Aykins et al., 2003). Ingested lead is rapidly absorbed into the bloodstream and is believed to have adverse effects on the cardiovascular system, kidneys and liver (Bergeson et al., 2008). Ethanol increases the vulnerability of systematic toxicity of lead including nephrotoxicity, hepatotoxicity, and neurotoxicity (Flora et al., 2007). Lead and cadmium co-administration causes peripheral arterial disease, inhibition of the activity of superoxide dismutase, and impaired protein biosynthesis (Jaberen et al., 2010). High blood lead concentration is directly proportional to alcohol consumption (Robert et al., 1995).

\section{Conclusion}

Alcoholic solutions of salts of metals have adverse effect on biochemical parameter of the kidney and liver based on the results obtained. Some of these metals are introduced through material and containers used. There was increased serum concentration/activities of the liver and kidney parameters monitored after seven and fourteen days of the treatment. The adverse effects of treatments were more on the liver compared to the kidney. This may be due to fact that the liver is the primary site of metabolism. Hence, it is more vulnerable to the toxic effects of the metals, alcohol and its metabolites than the kidney.

\section{COMPETING INTERESTS}

The authors declare that they have no competing interest concerning this work.

\section{REFERENCES}

Adepoju-Bello AA, Ojomolade OO, Ayoola GA, Coker HAB. 2009. Quantitative analysis of some toxic metals in in domestic water obtained from Lagos metropolis. The Nig. J. Pharm., 42(1): 57-60.

Altamirano J, Fagundes C, Dominguez M, Garcia E, Michelena J, Cardenas A, Guevara M, Pereira G, Torres-Vigil K, Arroyo V, Caballeria J, Gines P, Bataller R. 2012. Acute kidney injury is an early predictor of mortality for patients with alcoholic hepatitis. Clin Gastroenterol Hepatol., 10: 65-71.

Asma S, Kamel K, MedSaleh B. 2014. Ethanol exposure induces liver and kidney injury in adult male rabbits. Annals of Biological Research, 5(4): 2326.

Aydemir TB, Luizi JP, McClellan S, Cousin RJ. 2009. Zinc transporter ZIP8 and zinc influence expression in activated human T Cells. J. Leukoc Biol., 86(2):337-348.

Aykins-Burns N, Laegeler A, Kellog G, Ercal N. 2003. Oxidative effects of lead in young and adult Fisher 344 rats. Archive of Environmental Contamination Toxicology, 44: 417-420.

Bergeson LL. 2008. The proposed lead NAAQS: Is consideration of cost in the clean air act's future? Environmental Quality Management, 18:79-84.

Bonses RW, Tausskay HH. 1945. Colorimetric determination of Creatinine by the Jaffe's reaction. Journal of Biological Chemistry, 158: 581-591.

Brust JC. 2010. Ethanol and cognition: indirect effects, neurotoxicity and 
neuroprotection: a review. Int $J$ Environ Res Public Health., 7(4):1540-1557.

Epstein M. 1997. Alcohol's impact on kidney function test. Alcohol and Health Res. World, 21(1): 84-93.

Erhirhe EO, Ekene NE, Ajaghaku DL. 2014. Guidelines on dosage calculation and stock solution preparation in experimental animal studies. Journal of Natural Sciences Research, 4(18): 100106.

Fearon WR. 1939. Colorimetric determination of Urea in samples. Biochem. Journal, 33: 902-903.

Flora SJS, Singh S, Tandon SK. 1989. Thiamine and zinc in prevention or therapy of lead intoxication. Journal of International Medical Research, 17(1): 68-75.

Frank JK, Witte K, Schrodi W, Schutt C. 2004. Chronic alcoholism causes deleterious conditioning of innate immunity. Alcohol and Alcoholism, 39: 386-392.

Gazuwa SY, Dabak JD, Ubom GA. 2006. Iron Contamination of Two Local Alcoholic Drinks. J. Med. in the Tropics, 8(1): 4143.

Gazuwa SY, Dabak JD, Ubom G A. 2008. Contaminants in local alcoholic beverages: zinc and manganese contamination. International Journal of Biological and Chemical Sciences, 2(4): 411-416.ii

Gazuwa SY, Dabak JD, Ubom GA. 2012. Effects of alcoholic solutions of some metals on some nephrotic and hepatic biochemical parameters in male albino Wistar rats in vivo. Asian Journal of Experimental Biological Sciences, 3(2): 431-434.

Gazuwa SY, Dabak JD, Ubom GA. 2014. Consequences of in vivo interactions of binary mixtures of salts of metals in alcoholic milieu on the liver and kidney of male albino Wistar rats. IOSR
Journal of Pharmacy and Biological Sciences., 9(3): 23-27.

Gornail AG, Bardawill CJ, David MM 1949. Determination of serum Proteins by the Biuret eaction. Journal of Biological Chemistry, 177: 751-766.

Jaberen RM, Waqas S. 2010. Teratogenic effects of lead acetate on the Kidney. Journal of Ayub Medical College, 22(1): 76-82.

Kang YJ, Zhou Z. 2005. Zinc prevention and treatment of alcoholic liver disease. $\mathrm{Mol}$ Aspects Med, 26: 391-404.

Kono H, Arteel GE, Rusyn I. 2001. Ebselen prevents early alcohol-induced liver injury in rats. Free Radical Biology \& Medicine, 30: 403-411.

Lieber SC. 2005. The Discovery of the Microsomal Ethanol Oxidizing System and Its Physiologic and Pathologic Role. Drug Metabolism Reviews, 36: 511-529.

Lind Y, Engman J, Jorhem L, Glynn AW. 1998. Accumulation of Cadmium from wheat bran, sugar-beet fibre, Carrots and Cadmium chloride in the Liver and Kidneys of Mice. British Journal of Nutrition, 80(5): 205-211.

Maduabuchi JMU, Nzegwu CN, Adiga EO, Alonke RU, Ezomike CN, Okocha CE, Obi E Orisakwe OE. 2006. Lead and cadmium exposures from canned and non-canned beverages in Nigeria; a public health concern. Science of the Total Environment, 366: 621-626.

Maria D, Xuelong D, Haihong Z, Allessandria C, Luigi M, Tiziana T, Massimo $\mathrm{P}$, Angelo C, Valeria R, Jefferey E, Michael B Ida G. 2009. Urea causes the generation of reactive oxygen species. $J$. Clin. Invest., 5(10): 1172-1177.

Marks JS, Naimi TS, Brewer RD, Mokdad A, Denny C, Serdula MK. 2003 Binge drinking among U. S. adults. JAMA., 289: 70-75.

Mayer H, Macroni O, Floridi S, Montanari L, Fontozzi P. 2003. Determination of 
copper in beer by derivative potentiometric stripping analysis. Journal of the Institute of Brewing., 109(4): 332-336.

Pohl P. 2007a. Fractionation analysis of metals in dietary samples using ionexchange and adsorbing resins. Trends in Analytical Chemistry, 26(7): 713-726.

Reitman S, Frankel S. 1957. A colorimetric method for the determination of the activities of the transaminases and alkaline phosphatase. Journal of Clinical Pathology, 28: 56-63.

Robert AL, Dana RS, Tibiona KV. 1995. Interactions of lead nitrate and cadmium chloride with $\mathrm{E}$ coli $\mathrm{k}-12$ and $\mathrm{S}$ typhimurium global regulatory mutants. Journal of Industrial Microbiology, 14(3): 252-254.

Sema B, Pelin A, Sehnaz B, Refiye Y, Sevim T, Sukriye Y. 2006. Influence of zinc sulphate intake on acute ethanol- induced liver injury in rats. World Journal of Gastroenterology, 12(27): 43454351. DOI: 10.3748/wjg.v12.i27.4345.
Sherlock M, O'Sullivan E, Agha A, Behan LA, Owens D, Finucane F, Rawluk D, Tormey W, Thompson CJ. 2009. Incidence and pathophysiology of severe hyponatraemia in neurosurgical patients. Post Grad Med J., 85(1002):171-175. DOI: 10.1136/pgmj.2008.072819.

Thomas MM, Calivarathan, EN. 2014. Chronic alcohol ingestion induces oxidative kidney damage through taurine-inhibitable inflammation. Free Radical Biology and Medicine, 8: 403404.

Vize PD, Woolf AS, Bard JBL. 2003. The Kidney: From Normal Development to Congenital Disease. Cambridge University Press: Cambridge, United Kingdom; P 154.

Yang CF, Shen Y, Zhuang ZX, Ong CN. 2000. Cadmium-induced Oxidative Cellular damage in Human foetal Lung Fibroblasts (MRC-5-Cells). School of Public Health, Tongji, China. 